\section{ATLAS OF HISTOLOGIC DIAGNOSIS IN SURGICAL PATHOLOGY}

By K. T. Neubuerger, M.D. Pp. $x+460$, with 880 illustrations. London: Bailliere, Tindall and Cox. 1951. £4 4s.

This book is designed to augment the photomicrographic aspect of the standard surgical textbooks. It consists of 880 photomicrographs covering a great variety of pathological conditions, the text being restricted to short descriptions of the figures and brief notes on the clinical aspects.

The great majority of the illustrations are excellent photographs of good histological sections showing the relevant features of the particular conditions. A few of the photomicrographs are perhaps not up to the general standard, but in view of the tremendously wide field covered, this standard is exceptionally high.

Its high standard of illustration, together with the wide field of pathology covered will make this book invaluable to many surgeons and pathologists. The cost, moreover, is reasonable and compares very favourably with other recent publications of this nature.

\section{ANY QUESTIONS ?}

From the 'British Medical Journal' First Series. Pp. xii +240 . London: B.M.A 1951. 7s. 6d.

For several years a panel of experts have, eact week, answered questions sent to the British Medicat Fournal by medical men all over the world. This small book contains many of those questions anc: answers. The questions answered are varied and interesting. They not only cover ground on whiclon the general practitioner treads every day, but oftery touch on subjects which, while only occurring. infrequently, are rarely found in the text-books?

The replies have obviously been well considered and are excellent. True there are some with whicks a general practitioner may not agree entirely, but that only makes the book more readable.

On the flyleaf is a statement saying that this book is indispensable to the general practitioner ${ }_{\infty}$ This is an opinion to which the reviewer cannotw subscribe, but there is no doubt that no doctor, bev he general practitioner or consultant, can read this book without interest and without addings considerably to his store of knowledge. G.M.W. ڤे

\title{
ERRATUM
}

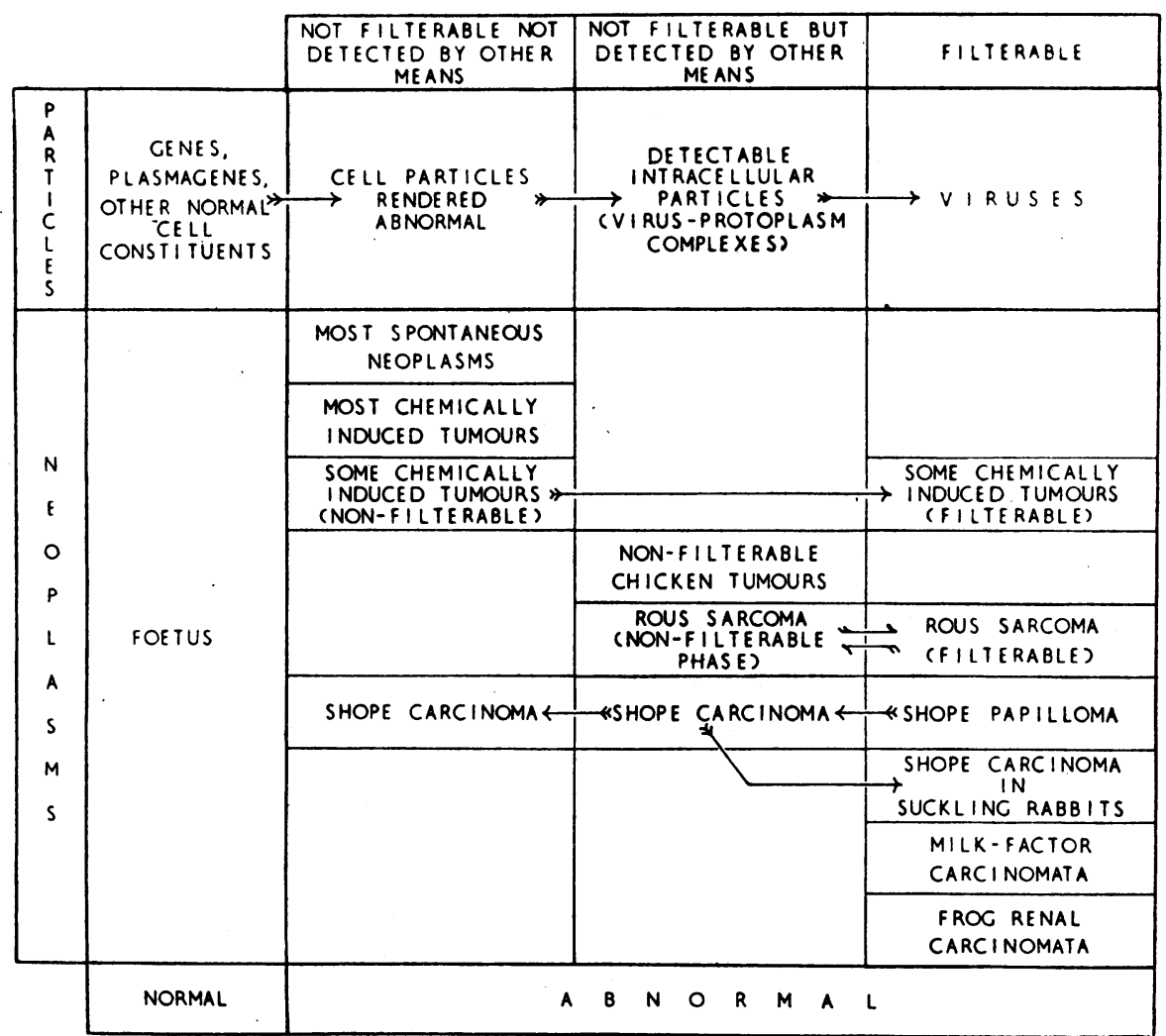

We much regret that the above table (Table I), referred to on pp. 25 and 26 of our January issue, was omitted from Dr. Warner's article. The Editor begs to offer his sincere apologies. 